\title{
GMR
}

\section{Upregulated microRNA-301a in osteosarcoma promotes tumor progression by targeting CDC14A}

\author{
Z. Ni, X.F. Shang, Y.F. Wang, Y.J. Sun and D.J. Fu \\ Department of Osteology, Anhui Provincial Hospital, Hefei, China \\ Corresponding author: X.F. Shang \\ E-mail: xifushang2004@163.com \\ Genet. Mol. Res. 15 (2): gmr.15027807 \\ Received October 8, 2015 \\ Accepted December 10, 2015 \\ Published May 23, 2016 \\ DOI http://dx.doi.org/10.4238/gmr.15027807
}

\begin{abstract}
MicroRNAs (miRs) are associated with tumor progression in various cancers, such as gastric and hepatic carcinomas, and lung cancer. miR-301a is overexpressed and displays oncogenic activity in cancers. We investigated the biological involvement of miR301a in osteosarcoma (OS). Quantitative real-time polymerase chain reaction (qRT-PCR) was used to analyze expression levels of miR-301a in $24 \mathrm{OS}$ and matched adjacent non-tumor tissues. A miR-301a mimic was transferred into OS cell lines U-2 OS and MG-63 to upregulate miR-301a. The effects of miR-301a were investigated by examining cell proliferation, migration, and the cell cycle. The miR-301 target was predicted by TargetScan and confirmed by western blotting and qRT-PCR. The expression of miR-301a was significantly higher in OS tissues compared with the matched adjacent non-tumor tissues $(0.959 \pm$ 0.39 vs $3.9516 \pm 1.18)$. Upregulated miR-301a significantly increased proliferation at 48 and $72 \mathrm{~h}$ compared to the negative control (U-2 OS: $2.11 \pm 0.21$ vs $2.88 \pm 0.24 ; 2.70 \pm 0.26$ vs $3.71 \pm 0.24$; MG-63: $2.19 \pm$ $0.20 v s 3.19 \pm 0.22 ; 3.1 \pm 0.25 v s 4.01 \pm 0.27)$ and migration capability (U-2 OS: $100 \pm 20.19$ vs $150.68 \pm 32.83$; MG-63: $100 \pm 17.20$ vs 133.35 $\pm 26.26)$, and decreased apoptosis in both U-2 OS (10.87 \pm 2.53 vs 4.01
\end{abstract}


$\pm 2.23)$ and MG-63 $(15.26 \pm 2.15$ vs $8.25 \pm 3.07)$. The cell cycle studies revealed that miR-301a caused an increase of the G2 population in U-2 OS $(38.6 \pm 6.58 v s 47.2 \pm 7.27)$ and MG-63 (44.01 \pm 5.28 vs $57.9 \pm$ 4.25). Additional experiments indicated that $\mathrm{CDC} 14 \mathrm{~A}$ was upregulated by miR-301a $(0.63 \pm 0.06 v s 0.98 \pm 0.06 ; 1.49 \pm 0.25 v s 2.99 \pm 0.14)$. Overexpressed miR-301a may increase CDC14A expression and promote cell proliferation and migration in OS cells. Therefore, miR301a may be useful for osteosarcoma diagnosis and therapy.

Key words: microRNA-301a; Osteosarcoma; $C D C 14 A$

\section{INTRODUCTION}

Osteosarcoma (OS) is the most frequent primary human sarcoma of the bone and a leading cause of cancer death, mainly in children and adolescents owing to its rapid proliferation (Mirabello et al., 2009; Jiang et al., 2014). Survival for these patients is poor, even following surgery and/or radiotherapy (Lewis, 2009; Cho et al., 2011). Therefore, the mechanisms by which effector molecules and signaling pathways affect the formation and development of OS have been extensively studied.

MicroRNAs (miRNAs) are a class of endogenous small non-coding RNAs that regulate various target mRNAs at the level of mRNA degradation or translation (Van Wynsberghe et al., 2011; Ameres and Zamore, 2013; Cipolla, 2014). They are regulated in several diseases including cancers, where they have been characterized as oncogenes, tumor suppressors, or as components of regulatory pathways that are critical for tumorigenesis (Tang and Fang, 2009; Suzuki et al., 2012). miRNAs have potential as biomarkers and therapeutic targets for various tissues and cells in a clinical context. To date, miRNAs and their roles in OS development have attracted much attention. Some of them, including miR-93, -124, -137, -150, -202, and -300 are involved in the initiation and progression of OS, and modulate the biological properties of cancer cells (Karbasy et al., 2015; Kawano et al., 2015; Li et al., 2015a; Li et al., 2015b; Lin et al., 2016; Zhang et al., 2015a).

The authors of a recent study reported that miR-301a is upregulated in pancreatic cancer via negative regulation of SMAD4 (Xia et al., 2015). Another study demonstrated that miR-301a regulates the function of myelin-reactive T-helper type 17 cells to control autoimmune demyelination (Mycko et al., 2012). These studies support the role of miR-301a as a candidate for therapeutic targets. However, the role of miR-301a in OS proliferation, invasion, and migration remains unknown.

In this study, we investigated the potential function of miR-301a in OS carcinogenesis and found that upregulation of miR-301a occurred in OS tissues compared with the corresponding adjacent tissues. In addition, an in vitro study revealed that upregulation of miR-301a significantly increased the proliferation and migration capability, and reduced apoptosis in both U-2 OS and MG-63 cell lines. The cell cycle studies revealed that miR301 a caused an increase of the $\mathrm{G} 2$ population. Additional experiments indicated that $C D C 14 \mathrm{~A}$ was upregulated by miR-301a. Overall, the results presented here elucidate the underlying mechanism by which miR-301a promotes OS growth and metastasis. 


\section{MATERIAL AND METHODS}

\section{Tissue samples}

Fresh samples from OS and the corresponding normal adjacent tissue were obtained from 24 patients undergoing surgery for OS at Anhui Provincial Hospital between January 2012 and October 2014. The samples were immediately snap-frozen in liquid nitrogen and stored at $-80^{\circ} \mathrm{C}$ until required for RNA extraction. The study was approved by the hospital ethical committee, and every patient received written informed consent.

\section{Cell culture and transfection}

The human OS cell lines U-2 OS and MG-63 were purchased from the Cell Bank of the Institute of Biochemistry and Cell Biology, China Academy of Sciences (Shanghai, China). The cells were maintained in Dulbecco's modiðed Eagle's medium (DMEM) (Gibco, Carlsbad, USA) containing $10 \%$ fetal bovine serum (FBS, Gibco, Carlsbad, USA) and cultured at $37^{\circ} \mathrm{C}$ in humidified air containing 5\% $\mathrm{CO}_{2}$. For transfection, cells were cultured to $80 \%$ confluence and transfected with $100 \mathrm{nM}$ miR-301a mimic and $100 \mathrm{nM}$ negative control (NC) using a ribo FECT ${ }^{\mathrm{TM}} \mathrm{CP}$ Transfection Kit (RiboBio Company, Guangzhou, China) according to the manufacturer instructions. Further treatment was carried out several hours after transfection.

\section{RNA extraction and quantitative real-time PCR (qRT-PCR)}

Total RNA, including miRNA, was extracted from the cell lines and tissue samples using TRIzol reagent (Invitrogen, USA). RNA was translated into complementary DNA (cDNA) using a reverse transcriptase kit (TaKaRa, Dalian, China). qRT-PCR was perforemdt using SYBR ${ }^{\circledR}$ Premix Ex Taq $^{\mathrm{TM}}$ (TaKaRa). PCR was performed in triplicate and analyzed using the ABI 7500 Fast Real-Time PCR system (Applied Biosystems, Life Technologies, USA). The relative quantification values for each miRNA were calculated by the $2^{-\Delta \Delta \mathrm{Ct}}$ method using U6 as an internal reference. The reverse transcriptase (RT) and PCR primers for miR-301a and U6 were purchased from RiboBio (Guangzhou, China).

\section{Proliferation assay}

A CCK-8 assay was used to analyze cell proliferation. U-2 OS and MG-63 cells were transfected with either the miR-301a mimic or an NC. After $24 \mathrm{~h}$ of transfection, the cells were seeded into a 96 -well plate at $5.0 \times 10^{3}$ cells/well and cultured for 24,48 , and $72 \mathrm{~h}$. At each time-point, $10 \mu \mathrm{L}$ CCK-8 reagent (Dojindo, Japan) was added to each well and the cells were incubated for $2 \mathrm{~h}$ at $37^{\circ} \mathrm{C}$. Spectrometric absorbance at a wavelength of $450 \mathrm{~nm}$ was measured using a microplate reader (Spectra Max M5; MD, USA). Each sample was tested in triplicate and all experiments were performed three times.

\section{Cell cycle analysis}

After $48 \mathrm{~h}$ transfection, the cell cycle was investigated using $100 \mathrm{mg} / \mathrm{mL}$ propidium iodide (PI) solution containing $50 \mathrm{mg} / \mathrm{mL}$ RNase (Beyotime, Haimen, China) for staining, and subsequently analyzed using FACScan cytofluorometry equipment (Becton Dickinson, NJ, USA). 


\section{Apoptosis analysis}

Cells were transfected as above; $48 \mathrm{~h}$ after transfection, the cells were harvested and washed with ice-cold phosphate-buffered saline (PBS), then stained using an Annexin V Apoptosis Detection Kit (BD Pharmingen, USA). This was followed by flow cytometry analysis. The test was conducted in triplicate per experiment.

\section{Cell migration analysis}

The cell migration experiment was performed using Transwell polycarbonate membrane inserts (Millipore, Schwalbach, Germany) on 24-well plates. The cells $\left(5 \times 10^{4}\right)$ were plated onto the chamber and vascular endothelial growth factor (VEGF) $(50 \mathrm{ng} / \mathrm{mL})$ was added to the cellfree medium in the lower chamber. After incubation for $24 \mathrm{~h}$ at $37^{\circ} \mathrm{C}$, the inserts were rinsed in PBS, and the cells were fixed to the membranes with $4 \%$ paraformaldehyde and stained with Hoechst $(10 \mathrm{mg} / \mathrm{mL})$. The migrated cells were counted at high-power field.

\section{Western blotting}

Cells were transfected as above and $48 \mathrm{~h}$ later the total cell extracts were prepared from the cells using Cell and Tissue Protein Extraction Regent (KangChen Bio-Tech, China). Electrophoresis of the samples was carried out on $10 \%$ sodium dodecyl sulfate polyacrylamide gel. The proteins were then transferred to nitrocellulose filter membranes. The membranes were blocked for $1 \mathrm{~h}$ in $5 \%$ bovine serum albumin (BSA) and incubated with CDC14A or glyceraldehyde 3-phosphate dehydrogenase

(GAPDH) antibody (1:1000; Cell Signaling Technology, USA) overnight at $4^{\circ} \mathrm{C}$, followed by incubation with the appropriate IRDye $800 \mathrm{CW}$-conjugated secondary antibody (1:5000; LI-COR Biosciences, USA). The infrared fluorescence images were obtained using an Odyssey Infrared Imaging System (LI-COR Biosciences).

\section{Statistical analysis}

Data are reported as means \pm SD. Graphs were drawn using GraphPad Prism v5.0. Data were analyzed using one-way analysis of variance (ANOVA) followed by a $t$-test. Differences with $\mathrm{P}<0.05$ were considered statistically signiðcant.

\section{RESULTS}

\section{miR-301a is significantly upregulated in OS tissues}

To examine the changes of the miR-301a expression in cases of OS, the expression of miR-301a was examined in 24 OS tissue specimens. As shown in Figure1, the expression level of miR-301a was significantly elevated in the primary tumor tissue of patients compared with the corresponding adjacent normal tissue $(0.959 \pm 0.39$ vs $3.9516 \pm 1.18)$. The results of this analysis suggest a relationship between miR-301a and OS. Based on this expression pattern, we therefore chose U-2 OS and MG-63 cells for the following gain-of-function and loss-offunction studies, respectively. 


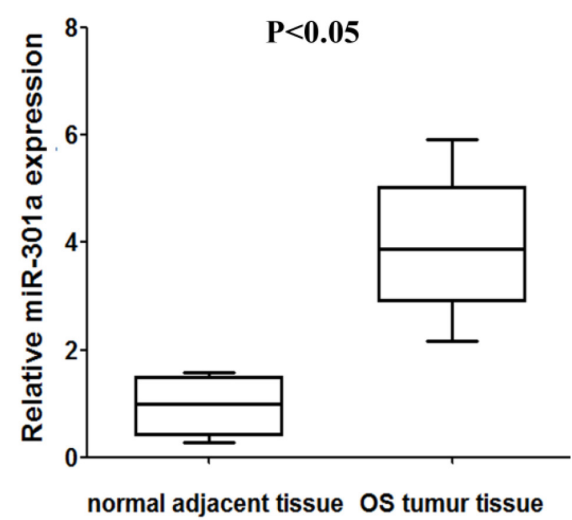

Figure 1. miR-301a shows high expression in osteosarcoma (OS) tumor tissue specimens. Quantitative real-time polymerase chain reaction (qRT-PCR) analysis of miR-301a expression in 24 pairs of primary OS tumor tissue and their corresponding adjacent tissues.

\section{miR-301a promotes cell proliferation while inhibiting cell apoptosis in the OS cell lines}

To detect the functional roles of miR-301a, we then examined the effect of miR$301 \mathrm{a}$ on cell proliferation, the cell cycle, and cell apoptosis. The CCK-8 assay showed that transfection of the miR-301a mimic significantly promoted cell proliferation in the U-2 OS at 48 and $72 \mathrm{~h}$ compared with the negative control $(2.11 \pm 0.21 v s 2.88 \pm 0.24 ; 2.70 \pm 0.26 v s$ $3.71 \pm 0.24)$, and MG-63 cell proliferation was also been promoted at 48 and $72 \mathrm{~h}(2.19 \pm 0.20$ vs $3.19 \pm 0.22 ; 3.1 \pm 0.25$ vs $4.01 \pm 0.27$ ). (Figure 2A-2B). Furthermore, to investigate the promotion of cell proliferation, we determined the populations of different cell phases in the cell cycle. We found that overexpression of miR-301a significantly increased the population of G2 phase cells in U-2 OS (38.6 $\pm 6.58 v s$ 47.2 \pm 7.27 ; Figure 2C) and MG-63 (44.01 \pm 5.28 vs $57.9 \pm 4.25$; Figure 2D). Additionally, flow cytometry analysis showed that upregulation of miR-301a in both U-2 OS and MG-63 cells inhibited cell apoptosis compared with the control group $(10.87 \pm 2.53$ vs $4.01 \pm 2.23$, Figure $2 \mathrm{E}$; $15.26 \pm 2.15$ vs $8.25 \pm 3.07$, Figure $2 \mathrm{~F})$.

\section{miR-301a promotes migration in the OS cell lines}

The Transwell assays showed that the migration of both the U-2 OS cells $(100 \pm 20.19$ vs $150.68 \pm 32.83$; Figure $3 \mathrm{~A})$ and the MG-63 cells $(100 \pm 17.20$ vs $133.35 \pm 26.26$; Figure 3B) significantly increased after transfection with the miR-301a mimic.

\section{CDC14A is a target of miR-301a in OS cell lines}

To gain further insight into the molecular mechanism by which miR-301a affects OS cells, we searched for genes that are targeted by miR-301a using biological target prediction software (TargetScan); CDC14A attracted our attention. The expression levels of both CDC14A protein $(0.63 \pm 0.06$ vs $0.98 \pm 0.06 ; 1.49 \pm 0.25$ vs $2.99 \pm 0.14$; Figure 4A-4B) and CDC14A mRNA ( $1.17 \pm 0.24$ vs $3.09 \pm 0.73 ; 1.1 \pm 0.14$ vs $3.92 \pm 0.39$; Figure 4C-4D) in the U-2 OS and MG-63 cells were dramatically increased by miR-301a. 



Figure 2. miR-301a promotes cell proliferation while inhibiting cell apoptosis in osteosarcoma (OS) cell lines. CCK-8 assay of cells transfected with miR-301a or miR-NC for the indicated number of hours in U-2 OS (A) and MG-63 (B) (NC = negative control); cell cycle progression assay of cells transfected with miR-301a or miR-NC in U-2 OS (C) and MG-63 (D); apoptosis assay of cells transfected with miR-301a or miR-NC in U-2 OS (E) and MG-63 (F); *P $<0.05$ vs miR-NC, **P $<0.01$ vs miR-NC.

A

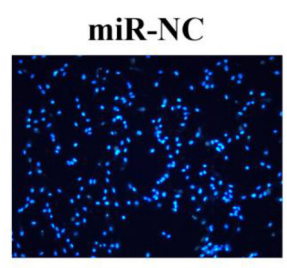

B



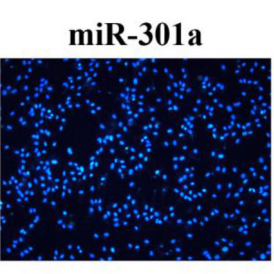

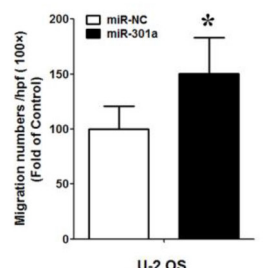

U-2 OS
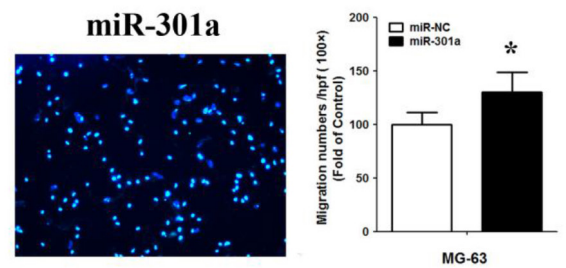

Figure 3. miR-301a promotes osteosarcoma (OS) cell line migration. Transwell assays of cells transfected with miR-301a or miR-NC showing the effects on migration of U-2 OS (A) and MG-63 (B) (NC = negative control); $100 \mathrm{X}$ original magnification; $* \mathrm{P}<0.05 v s$ miR-NC. 

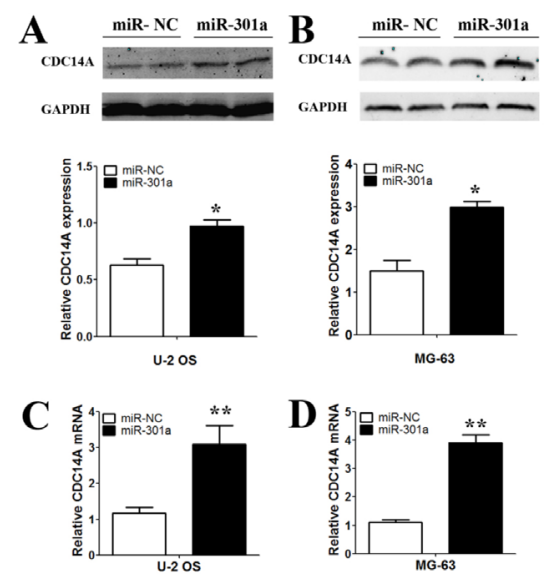

Figure 4. $C D C 14 A$ is a target of miR-301a in osteosarcoma (OS) cell lines. Western blotting analyses of $C D C 14 A$ expression in U-2 OS (A) and MG-63 (B) cells transfected with miR-301a or miR-NC (NC = negative control); the expression level of $\beta$-actin was used as a control. Representative western blots are shown. CDC14A mRNA expression in U-2 OS (C) and MG-63 (D) cells transfected with a miR-301a or miR-NC; ${ }^{*} \mathrm{P}<0.05$ vs miR-NC, $* * \mathrm{P}<0.01$ vs miR-NC.

\section{DISCUSSION}

Osteosarcoma is an aggressive malignant osteoid that grows from the cancerization of cells of mesenchymal origin, which inhibit osteoblastic differentiation (Tian et al., 2015). The low rate of survival in patients treated with multi-agent therapy necessitates further research into the mechanism underlying OS carcinogenesis. A large number of miRNAs are located inside or close to fragile chromosomal sites that are frequently lost or amplified in cancers, and the correlation between miRNAs and cancer has become a focus for the diagnosis and therapy of cancer (Calin et al., 2004). In this study, we found that the expression of miR-301a was significantly higher in OS tissue compared with the matched adjacent non-tumor tissue. This outcome indicates that miR-301a is involved in the pathogenesis of OS.

miRNAs can act as oncogenes or tumor suppressors, and are involved in numerous cellular processes, playing roles in tumorigenesis by regulating cell differentiation, cell proliferation, and the cell cycle (Song and Ju, 2010; Rottiers et al., 2011; Sandoval and Esteller, 2012; Schotte et al., 2012). miR-301a has also been shown to have a cancerous function in several human tumors, such as pancreatic, prostate, colorectal, and breast cancers (Ma et al., 2014; Zhang et al., 2014; Xia et al., 2015; Xie et al., 2015). Furthermore, miR-301a expression is associated with radiotherapy resistance ( $\mathrm{Su}$ et al., 2014). However, the role of miR-301a in OS tumor development and metastasis has only recently been investigated and remains largely unknown. In this study, we found that upregulation of miR-301a significantly increased proliferation in both U-2 OS and MG-63 cells. Moreover, the cell cycle studies revealed that miR-301a caused an increase of the G2 phase population. In addition, overexpression of miR301a markedly reduced apoptosis in both U-2 OS and MG-63 cells. These data suggest that the increased expression of miR-301a contributes to the growth of OS cells, and consequently facilitates the advanced development of OS. We also discovered that the migration capability of U-2 OS and MG-63 cells was enhanced after transfection with the miR-301a mimic. This 
result indicates that an aberrant increase in the level of miR-301a may promote cell migration in OS cell lines. Thus, we confirmed that miR-301a may be a tumor oncogene in OS.

A single miRNA can coordinate a large number of target genes (Lim et al., 2005). Several miR-301a targets have been identified in different cells, such as SMAD4, TGF-b1, and AMPK (Xia et al., 2015; Xie et al., 2015; Zhang et al., 2015b). To investigate the mechanism by which miR-301a influences OS oncogenesis, we used TargetScan to identify possible mRNA targets, and CDC14A attracted our attention. CDC14A can act independently of its function in the cell cycle (Clément et al., 2012). CDC14A has been identified as a regulator of centrosome duplication, and it has been suggested that it participates in the control of mitotic entry (Mailand et al., 2002). In addition, CDC14A phosphatase impairs the timing of mitotic entry by affecting cyclin-dependent kinase 1 (CDK1)-cyclin B1 activity (Vázquez-Novelle et al., 2010). Here, we used qRT-PCR and western blotting analysis to determine whether the expression of $C D C 14 A$ was upregulated after miR-30a transfection in OS cell lines. We confirmed that $C D C 14 A$ is one of the target genes of miR-301a.

In conclusion, our data suggest that miR-301a might be useful as a biomarker of potentially malignant tumors. We also demonstrated that miR-301a promotes proliferation and migration, and reduces apoptosis by targeting $C D C 14 A$ in osteosarcoma. Thus, miR-301a may be a useful tool in OS diagnosis and therapy.

\section{Conflicts of interest}

The authors declare no conflict of interest.

\section{ACKNOWLEDGMENTS}

Research supported by grants from the Natural Science Foundation of Anhui Province, China (\#1208085QH161).

\section{REFERENCES}

Ameres SL and Zamore PD (2013). Diversifying microRNA sequence and function. Nat. Rev. Mol. Cell Biol. 14: 475-488. http://dx.doi.org/10.1038/nrm3611

Calin GA, Sevignani C, Dumitru CD, Hyslop T, et al. (2004). Human microRNA genes are frequently located at fragile sites and genomic regions involved in cancers. Proc. Natl. Acad. Sci. USA 101: 2999-3004.http://dx.doi.org/10.1073/ pnas.0307323101

Cho Y, Jung GH, Chung SH, Kim JY, et al. (2011). Long-term survivals of stage IIb osteosarcoma: a 20-year experience in a single institution. Clin. Orthop. Surg. 3: 48-54. http://dx.doi.org/10.4055/cios.2011.3.1.48

Cipolla GA (2014). A non-canonical landscape of the microRNA system. Front. Genet. 5: 337-342. http://dx.doi. org/10.3389/fgene.2014.00337

Clément A, Solnica-Krezel L and Gould KL (2012). Functional redundancy between Cdc14 phosphatases in zebrafish ciliogenesis. Dev. Dyn. 241: 1911-1921. http://dx.doi.org/10.1002/dvdy.23876

Jiang L, Tao C, He A and He X (2014). Overexpression of miR-126 sensitizes osteosarcoma cells to apoptosis induced by epigallocatechin-3-gallate. World J. Surg. Oncol. 12: 383-389. http://dx.doi.org/10.1186/1477-7819-12-383

Karbasy SH, Taheriazam A, Mirghasemi A, Sedaghati F, et al. (2015). Upregulation of miR-300 and downregulation of miR-125b act as potential predictor biomarkers in progression, metastasis, and poor prognosis of osteosarcoma. Tumour Biol. [Epub ahead of print] http://dx.doi.org/10.1007/s13277-015-4000-3

Kawano M, Tanaka K, Itonaga I, Ikeda S, et al. (2015). microRNA-93 promotes cell proliferation via targeting of PTEN in Osteosarcoma cells. J. Exp. Clin. Cancer Res. 34: 76-86. http://dx.doi.org/10.1186/s13046-015-0192-z

Lewis VO (2009). What's new in musculoskeletal oncology. J. Bone Joint Surg. Am. 91: 1546-1556. http://dx.doi. org/10.2106/JBJS.I.00375 
Li X, Chen L, Wang W, Meng FB, et al. (2015a). MicroRNA-150 Inhibits Cell Invasion and Migration and Is Downregulated in Human Osteosarcoma. Cytogenet. Genome Res. 146: 124-135. http://dx.doi.org/10.1159/000437379

Li ZM, Zhang HY, Wang YX and Wang WB (2015b). MicroRNA-137 is downregulated in human osteosarcoma and regulates cell proliferation and migration through targeting FXYD6. J. Drug Target. 24: 1-9.

Lim LP, Lau NC, Garrett-Engele P, Grimson A, et al. (2005). Microarray analysis shows that some microRNAs downregulate large numbers of target mRNAs. Nature 433: 769-773. http://dx.doi.org/10.1038/nature03315

Lin Z, Song D, Wei H, Yang X, et al. (2016). TGF-b1-induced miR-202 mediates drug resistance by inhibiting apoptosis in human osteosarcoma. J. Cancer Res. Clin. Oncol. 142: 239-246. http://dx.doi.org/10.1007/s00432-015-2028-9

Ma F, Zhang J, Zhong L, Wang L, et al. (2014). Upregulated microRNA-301a in breast cancer promotes tumor metastasis by targeting PTEN and activating Wnt/ $\beta$-catenin signaling. Gene 535: 191-197. http://dx.doi.org/10.1016/j. gene.2013.11.035

Mailand N, Lukas C, Kaiser BK, Jackson PK, et al. (2002). Deregulated human Cdc14A phosphatase disrupts centrosome separation and chromosome segregation. Nat. Cell Biol. 4: 317-322. http://dx.doi.org/10.1038/ncb777

Mirabello L, Troisi RJ and Savage SA (2009). Osteosarcoma incidence and survival rates from 1973 to 2004: data from the Surveillance, Epidemiology, and End Results Program. Cancer 115: 1531-1543. http://dx.doi.org/10.1002/ cncr.24121

Mycko MP, Cichalewska M, Machlanska A, Cwiklinska H, et al. (2012). MicroRNA-301a regulation of a T-helper 17 immune response controls autoimmune demyelination. Proc. Natl. Acad. Sci. USA 109: E1248-E1257. http://dx.doi. org/10.1073/pnas.1114325109

Rottiers V, Najafi-Shoushtari SH, Kristo F, Gurumurthy S, et al. (2011). MicroRNAs in metabolism and metabolic diseases. Cold Spring Harb. Symp. Quant. Biol. 76: 225-233. http://dx.doi.org/10.1101/sqb.2011.76.011049

Sandoval J and Esteller M (2012). Cancer epigenomics: beyond genomics. Curr. Opin. Genet. Dev. 22: 50-55. http:// dx.doi.org/10.1016/j.gde.2012.02.008

Schotte D, Pieters R and Den Boer ML (2012). MicroRNAs in acute leukemia: from biological players to clinical contributors. Leukemia 26: 1-12. http://dx.doi.org/10.1038/leu.2011.151

Song B and Ju J (2010). Impact of miRNAs in gastrointestinal cancer diagnosis and prognosis. Expert Rev. Mol. Med. 12: e33.http://dx.doi.org/10.1017/S1462399410001663

$\mathrm{Su}$ H, Jin X, Zhang X, Xue S, et al. (2014). Identification of microRNAs involved in the radioresistance of esophageal cancer cells. Cell Biol. Int. 38: 318-325.http://dx.doi.org/10.1002/cbin.10202

Suzuki H, Maruyama R, Yamamoto E and Kai M (2012). DNA methylation and microRNA dysregulation in cancer. Mol. Oncol. 6: 567-578.http://dx.doi.org/10.1016/j.molonc.2012.07.007

Tang JT and Fang JY (2009). MicroRNA regulatory network in human colorectal cancer. Mini Rev. Med. Chem. 9: 921926. http://dx.doi.org/10.2174/138955709788681672

Tian X, Zhang J, Yan L, Dong JM, et al. (2015). MiRNA-15a inhibits proliferation, migration and invasion by targeting TNFAIP1 in human osteosarcoma cells. Int. J. Clin. Exp. Pathol. 8: 6442-6449.

Van Wynsberghe PM, Chan SP, Slack FJ and Pasquinelli AE (2011). Analysis of microRNA expression and function. Methods Cell Biol. 106: 219-252. http://dx.doi.org/10.1016/B978-0-12-544172-8.00008-6

Vázquez-Novelle MD, Mailand N, Ovejero S, Bueno A, et al. (2010). Human Cdc14A phosphatase modulates the G2/M transition through Cdc25A and Cdc25B. J. Biol. Chem. 285: 40544-40553. http://dx.doi.org/10.1074/jbc. M110.133009

Xia X, Zhang K, Cen G, Jiang T, et al. (2015). MicroRNA-301a-3p promotes pancreatic cancer progression via negative regulation of SMAD4. Oncotarget 6: 21046-21063.http://dx.doi.org/10.18632/oncotarget.4124

Xie H, Li L, Zhu G, Dang Q, et al. (2015). Infiltrated pre-adipocytes increase prostate cancer metastasis via modulation of the miR-301a/androgen receptor (AR)/TGF-b1/Smad/MMP9 signals. Oncotarget 6: 12326-12339. http://dx.doi. org/10.18632/oncotarget. 3619

Zhang C, Hu Y, Wan J and He H (2015a). MicroRNA-124 suppresses the migration and invasion of osteosarcoma cells via targeting ROR2-mediated non-canonical Wnt signaling. Oncol. Rep. 34: 2195-2201.

Zhang W, Zhang T, Jin R, Zhao H, et al. (2014). MicroRNA-301a promotes migration and invasion by targeting TGFBR2 in human colorectal cancer. J. Exp. Clin. Cancer Res. 33: 113-125.http://dx.doi.org/10.1186/s13046-014-0113-6

Zhang Y, Duan G and Feng S (2015b). MicroRNA-301a modulates doxorubicin resistance in osteosarcoma cells by targeting AMP-activated protein kinase alpha 1. Biochem. Biophys. Res. Commun. 459: 367-373. http://dx.doi. org/10.1016/j.bbrc.2015.02.101 